\title{
Qualidade da arborização viária do campus da Universidade Federal de Viçosa
}

Dentre todas as formas de vegetação nas cidades, a arborização de ruas é a que está mais próxima da população e também é a que sofre maior influência dos elementos da urbanização, sendo por esses motivos que necessita de maior atenção por parte dos órgãos gestores. Dessa forma, o presente estudo objetivou avaliar a qualidade da arborização viária presente no Campus da UFV, identificando as espécies e verificando a adequação das mesmas ao local de plantio. Foram identificados todos os arranjos paisagísticos, e por meio de amostragem aleatória se selecionou um transecto de $100 \mathrm{~m}$ para realização da análise qualitativa em cada arranjo. No levantamento da arborização viária do Campus, foram identificados 389 indivíduos pertencentes a 19 espécies com predominância de exóticas. Foram identificados $24,7 \%$ de conflitos com a rede aérea e $30,2 \%$ de conflitos com a rede subterrânea. A prática de podas se mostrou mais frequente, com $81,4 \%$ de ocorrência nos indivíduos. Das espécies identificadas, apenas Handroanthus serratifolius, Michelia champaca, Anadenanthera colubrina, Ligustrum lucidum Archontophoenix cunninghamiana e Roystonea oleracea não apresentaram conflitos com os elementos urbanos, para as demais espécies há necessidade de suspender o plantio ou adequar os locais caso continuem sendo plantadas. De modo geral, é necessário um melhor planejamento e manejo da arborização do Campus visando aumentar a adequação e qualidade das espécies.

Palavras-chave: Floresta urbana; Arranjos paisagísticos; Diagnóstico da arborização.

\section{Quality of road afforestation on the campus of the Federal University of Viçosa}

\begin{abstract}
Among all forms of vegetation in cities, the streets tree is the one that is closest to the population and is also the one that suffers the greatest influence from the elements of urbanization, and for these reasons it needs more attention from the management bodies. Thus, the present study aimed to assess the quality of streets tree present at the UFV campus, identifying the species and checking their suitability for the planting site. All landscape arrangements were identified, and through random sampling, a $100 \mathrm{~m}$ transect was selected to perform qualitative analysis in each arrangement. In the survey of the road afforestation of the campus, 389 individuals were identified belonging to 19 species with predominance of exotic species. $24.7 \%$ of conflicts with the aerial network and $30.2 \%$ of conflicts with the underground network were identified. The practice of pruning was more frequent, with $81.4 \%$ of occurrence in individuals. Of the species identified, only Handroanthus serratifolius, Michelia champaca, Anadenanthera colubrina, Ligustrum lucidum, Archontophoenix cunninghamiana and Roystonea oleracea did not present conflicts with urban elements, for the other species there is a need to suspend planting or if they continue to be planted adjust the locations. In general, better planning and management of the afforestation of the Campus is necessary in order to increase the adequacy and quality of species.
\end{abstract}

Keywords: Urban forest; Landscape arrangements; Diagnosis of afforestation.

Topic: Planejamento, Gestão e Políticas Públicas Ambientais

Reviewed anonymously in the process of blind peer.
Received: 01/02/2020

Approved: 07/03/2020

Angeline Martini (iD)

Universidade Federal de Viçosa, Brasil

http://lattes.cnpq.br/1793083628826054

http://orcid.org/0000-0002-4500-1221

martini.angeline@gmail.com

Josilene Aguiar Canguçu (iD

Universidade Federal de Viçosa, Brasil

http://lattes.cnpq.br/9832025600926233

http://orcid.org/0000-0002-3259-9092

aguiarc.josilene@gmail.com

d

DOI: 10.6008/CBPC2179-6858.2020.002.0038
Referencing this:

MARTINI, A.; CANGUÇU, J. A.. Qualidade da arborização viária do campus da Universidade Federal de Viçosa. Revista Ibero Americana de Ciências Ambientais, v.11, n.2, p.418-433, 2020. DOI: http://doi.org/10.6008/CBPC2179-6858.2020.002.0038 


\section{INTRODUÇÃO}

Devido as necessidades de infraestrutura do meio urbano a cobertura vegetal original é modificada, fazendo com que a biodiversidade seja deteriorada e a degradação paisagística e ambiental tornem-se um problema significativo que deve ser solucionado (PERIOTTO et al., 2016). Uma das formas de reverter tal situação é promover o aumento da quantidade de vegetação nas cidades, principalmente por meio da arborização.

Entende-se por arborização urbana qualquer vegetação que compõe a paisagem urbana, independente do porte (BIONDI, 2008). Entre as categorias de arborização é comum que se confunda áreas verdes e arborização de ruas, sendo esta última correspondente a vegetação arbórea plantada linearmente em ambientes antropizados, com presença de calçadas, asfalto e população urbana, enquanto áreas verdes são definidas como o produto de um processo paisagístico que pode apresentar diferentes graus de antropização (BIONDI, 2015).

A arborização urbana exerce diversas funções, como: melhoria no microclima, diminuição da poluição do ar, sonora e visual, abrigo para fauna local e ajuda na composição da identidade urbanística perante as comunidades, sendo esses benefícios favoráveis a conexão com a natureza no ambiente urbano (BASSO et al., 2014). Entretanto, quando planejada inadequadamente pode ocasionar problemas irreversíveis, gerando conflitos (PERIOTTO et al., 2016), na rede elétrica e telefônica, na estrutura dos pavimentos e nas redes de esgoto (MIRANDA et al., 2009), entre outros, como a queda de folhas, flores e frutos, obstáculo para a iluminação noturna e obstrução de placas de orientação (RIBEIRO, 2009).

Dentre as formas de vegetação das cidades, a arborização de ruas sofre maior influência dos elementos da urbanização, além de interferências antrópicas indesejáveis e manejo inadequado, por isso precisa de atenção maior. Tais fatores levam a necessidade de identificação e uso de mais espécies adaptadas, além de um planejamento cuidadoso com objetivo de maximizar as funções da arborização e reduzir custos, evitando os problemas frequentemente apontados (MENEGHETTI, 2003).

É importante destacar ainda, que uma área pode ter muitas árvores e ser mal arborizada, bem como pode ter poucas árvores e ser bem arborizada (SILVA et al., 2007). Segundo os mesmos autores, a emissão de uma opinião correta precisa se embasar em um estudo detalhado, o qual chamamos de diagnóstico, que oferece resultados sobre a qualidade a partir de variáveis como: disponibilidade de espaço para desenvolvimento, fitossanidade (CEMIG, 2011), remoção e replantio, injúrias, necessidade de podas, exigência de outras intervenções (MELO et al., 2007) além de indicar a espécie apropriada para cada local, (REZENDE et al., 2010).

O primeiro Campus da Universidade Federal de Viçosa (UFV), se destaca em inúmeras reportagens que abordam os Campi universitários mais bonitos do Brasil e um dos principais fatores para esse reconhecimento se deve a integração dos elementos construtivos com os naturais. Além de proporcionar espaço para atividades de lazer e recreação, conferindo-lhe importância para os munícipes e universitários, deve- se destacar que o Campus serve como laboratório de pesquisa na área de arborização, devido a 
expressiva quantidade de árvores existentes, sendo comum a emissão de opiniões em larga escala sobre a qualidade da arborização local.

Dada a importância de avaliar as árvores localizadas no acompanhamento viário do Campus, por meio da identificação das condições atuais das espécies. Este trabalho teve como objetivo analisar a qualidade da arborização presente no acompanhamento viário do Campus da UFV em Viçosa/MG, em busca de verificar a adequação das espécies ao ambiente e contribuir para o manejo adequado.

\section{MATERIAIS E MÉTODOS}

A avaliação da arborização foi realizada no Campus da UFV de área equivalente a 1.646,55 hectares (ALMEIDA et al., 2016) localizada no município de Viçosa ( $20^{\circ} 45^{\prime} 23^{\prime \prime} \mathrm{S}$ e $42^{\circ} 52^{\prime} 23^{\prime \prime} \mathrm{W}$ ) na Zona da Mata Mineira. A formação florestal da região é classificada como Floresta Estacional Semidecidual Submontana (OLIVEIRA FILHO et al., 1994). De acordo com a classificação Koppen, o clima na região é do tipo Cwa, mesotérmico (SOARES JÚNIOR, 2000), com chuvas mal distribuídas ao longo do ano, verões quentes e chuvosos e invernos secos e frios. A temperatura média do ar é de $19^{\circ} \mathrm{C}$ sendo a máxima de $26,1^{\circ} \mathrm{C}$ e a mínima de $14^{\circ} \mathrm{C}$ (CASTRO et al., 1973) e precipitação média anual de $1.248 \mathrm{~mm}$ apresentando déficit hídrico no período de maio a setembro e um excedente entre dezembro e março (SOARES JÚNIOR, 2000).

Para essa pesquisa foram identificados todos os arranjos paisagísticos que compõem a arborização viária do Campus da UFV. Entende-se por arranjo paisagístico os diferentes conjuntos de espécies, padrões de plantio e estrutura física dos espaços. A extensão (comprimento) de cada arranjo foi medida por meio de imagens de satélite, com auxílio da ferramenta de medição do Google Earth. Após essa medição os arranjos foram subdivididos em transectos de $100 \mathrm{~m}$, correspondente ao tamanho do menor arranjo encontrado. Por meio de amostragem aleatória selecionou-se em cada arranjo paisagístico um transecto para realizar a análise qualitativa. A amostragem total realizada para a arborização viária do Campus foi equivalente a 28,7\% da população. Segundo Escobedo et al. (2002), dependendo da variabilidade da floresta urbana, um inventário da arborização de ruas que contemple entre 5 e $10 \%$ do total é suficiente para fornecer estimativas adequadas quanto ao patrimônio arbóreo. As informações foram coletadas entre fevereiro e março de 2018. Para isso houve a elaboração de uma planilha de campo, adaptada da metodologia proposta por Milano (1984), sendo avaliados os seguintes parâmetros: a) Espécie - a identificação botânica, feita em campo considerou espécies arbóreas, arbustivas (conduzidas como arvoretas) e palmeiras, plantadas linearmente. Posteriormente o nome científico e família botânica foram conferidos no site do Jardim Botânico do Rio de Janeiro e do Missouri Botanical Garden; b) Localização - o posicionamento dos indivíduos na unidade amostral a que pertence, foi realizado por meio da atribuição de numeração sequencial em cada árvore amostrada, incluindo as mortas; c) Altura total - estimou-se visualmente a altura total dos indivíduos, com base nos parâmetros urbanos do entorno; d) Altura de bifurcação - a altura da primeira bifurcação foi categorizada em < ou > a 1,80 m, sendo aferida com uso de trena quando necessário; e) Área livre do canteiro - foi categorizada em > ou < a $1 \mathrm{~m}^{2}$; f) Largura da calçada - medida com trena do início do meio fio até o fim da pavimentação ou início de outra estrutura física; g) Distância da árvore até a rede subterrânea e rede 
aérea - foi medida a distância da árvore até a caixa de visita e foi verificada a existência ou não de conflitos com a rede aérea; h) Condições do sistema radicular - variável categórica, onde a escala atribuída foi: 1- raiz profunda (não aflora a superfície), 2- raiz pouco superficial (raiz aparente na superfície, em baixa quantidade), 3- raiz superficial (raiz aflora na superfície em grande quantidade); i) Condições estruturais - variável categórica, onde a escala atribuída foi: 1- árvore em ótimo estado (sem nenhum problema aparente), 2 árvore em estado intermediário (com danos estruturais aparente - cancro, compartimentalização incompleta), 3 - árvore ruim (com desequilíbrio estrutural - torta, inclinada, só um lado de copa); j) Condições fitossanitárias - variável categórica, onde a escala atribuída foi: 1 - boa (indivíduo saudável), 2 - satisfatória (com problemas, mas que não comprometam a estrutura física ou condições fisiológicas da árvore), 3 - ruim (problemas estruturais, fisiológicos, com sinais de declínio ou morta); k) Condições Estética - variável categórica, onde a escala atribuída foi: 1 - boa (árvores em ótimo estado), 2 -intermediário (árvores descaracterizadas, mas com aparência agradável), 3 - ruim (árvores descaracterizadas e com aparência indesejável), 4 - muito ruim (árvores completamente deformadas); I) Intensidade de podas realizadas variável categórica, onde a escala atribuída foi: 1 - poda leve (remoção de poucos galhos e com diâmetros menores), 2- poda pesada (remoção de muitos galhos e de diâmetros maiores), 3 - poda drástica (destopo); m) Necessidade de poda e remoção - Identificação da necessidade de podas para atenuar conflitos com a estrutura urbana e necessidade de remoção devido a existência de indivíduos mortos ou em estágio avançado de senescência. As categorias atribuídas foram: 1) poda de levantamento; 2) poda direcional para desobstrução. 3) necessidade de remoção.

Os dados obtidos foram digitalizados em planilha do Microsoft Office Excel, onde foram realizadas análises necessárias em relação à amostragem efetuada. Os dados foram estruturados em gráficos e tabelas. A classificação das espécies em nativas e exóticas foi realizada com base nas informações do site Flora do Brasil e Trópicos e para o porte das árvores se consultou a literatura Silva Júnior et al. (2010). As variáveis altura de bifurcação, área de canteiro, largura da calçada, distância da árvore a rede aérea e subterrânea, condições do sistema radicular, estrutural, estética, fitossanidade e tipos de poda, foram distribuídas em classes adaptadas da metodologia de Milano (1984). Com base nas características do meio físico e das espécies encontradas, realizou-se a classificação das mesmas em adequadas ou não para plantio no acompanhamento viário do Campus.

\section{RESULTADOS}

A arborização viária existente no Campus da UFV é expressa por 19 padrões de arranjos paisagísticos que contribuem para formação da identidade visual dessas áreas, no qual representam a arborização viária do campus, com variações nas características físicas e elementos urbanos e com padrões de plantios diferentes. A amostragem das espécies que compõem a arborização viária do Campus foi composta por 389 indivíduos, destes, 243 são árvores (62,5\%), 83 arbustos (21,3\%) e 63 palmeiras (16,2\%), além de 8 indivíduos mortos: Murraya paniculata (3), Lagerstroemia indica (2), Bauhinia forficata (2) e Spathodea campanulata (1). 
Foram encontradas 19 espécies botânicas distribuídas entre 13 famílias (Tabela 1 . O maior número de indivíduos encontrado foi de Bauhinia forficata (15,9\%), seguido por Archontophoenix cunninghamiana $(13,6 \%)$ e Murraya paniculata (12,8\%).

Tabela 1: Relação das famílias, nome cientifico, nome popular, origem, total de indivíduos e Frequências das espécies amostradas.

\begin{tabular}{|c|c|c|c|c|}
\hline Família/Nome científico & Nome comum & 0 & Total & FR(\%) \\
\hline \multicolumn{5}{|l|}{ Fabaceae } \\
\hline Bauhinia forficata. Link & Pata de vaca & $\mathrm{E}$ & 62 & 15,9 \\
\hline Delonix regia (Bojer ex Hook.) Raf. & Flamboyant & $\mathrm{E}$ & 14 & 3,6 \\
\hline Anadenanthera colubrina var. cebil (Griseb.) Altschul & Angico vermelho & $\mathrm{N}$ & 1 & 0,3 \\
\hline Poincianella pluviosa var. peltophoroides (Benth.) L.P.Queiroz & Sibipiruna & $\mathrm{N}$ & 1 & 0,3 \\
\hline \multicolumn{5}{|l|}{ Arecaceae } \\
\hline Archontophoenix cunninghamiana H. Wendl. \&. Drude & Palmeira australiana & $\mathrm{E}$ & 53 & 13,6 \\
\hline Roystonea oleracea (Jacq.) O.F. Cook & Palmeira imperial & $\mathrm{E}$ & 10 & 2,6 \\
\hline \multicolumn{5}{|l|}{ Rutaceae } \\
\hline Murraya paniculata L. (Jack) & Murta & $\mathrm{E}$ & 49 & 12,6 \\
\hline \multicolumn{5}{|l|}{ Magnoliaceae } \\
\hline Michelia champaca (L.) Baill. ex Pierre & Magnólia & $\mathrm{E}$ & 34 & 8,7 \\
\hline \multicolumn{5}{|l|}{ Lythraceae } \\
\hline Lagerstroemia indica $\mathrm{L}$. & Resedá & $\mathrm{E}$ & 33 & 8,5 \\
\hline \multicolumn{5}{|l|}{ Bignoniaceae } \\
\hline Spathodea campanulata P. Beauv. & Espatódea & $\mathrm{E}$ & 26 & 6,7 \\
\hline Handroanthus serratifolius (Vahl) S.Grose & Ipê - Amarelo & $\mathrm{N}$ & 18 & 4,6 \\
\hline Handroanthus impetiginosus (Mart. ex DC.) Mattos & Ipê - Roxo & $\mathrm{N}$ & 9 & 2,3 \\
\hline \multicolumn{5}{|l|}{ Melastomataceae } \\
\hline Pleroma granulosum (Desr.) D. Don & Quaresmeira & $\mathrm{N}$ & 27 & 6,9 \\
\hline \multicolumn{5}{|l|}{ Chrysobalanaceae } \\
\hline Licania tomentosa (Benth.) Fritsch & Oitizeiro & $\mathrm{N}$ & 20 & 5,1 \\
\hline \multicolumn{5}{|l|}{ Proteaceae } \\
\hline Grevillea robusta $\mathrm{R} . \mathrm{Br}$. & Grevilha & $\mathrm{E}$ & 11 & 2,8 \\
\hline \multicolumn{5}{|l|}{ Combretaceae } \\
\hline Terminalia catappa L. & Chapéu de sol & $\mathrm{N}$ & 10 & 2,6 \\
\hline \multicolumn{5}{|l|}{ Myrtaceae } \\
\hline Callistemon viminalis (Sol.ex Gaertn.) G. Don & Escova de garrafa & $\mathrm{E}$ & 4 & 1,0 \\
\hline \multicolumn{5}{|l|}{ Sapindaceae } \\
\hline Litchi chinensis Sonn. & Lichia & $\mathrm{E}$ & 4 & 1,0 \\
\hline \multicolumn{5}{|l|}{ Oleaceae } \\
\hline Ligustrum lucidum W.T. Aiton. & Alfeneiro & $E$ & 3 & 0,8 \\
\hline Total & & & 389 & 100 \\
\hline
\end{tabular}

Nota: $\mathrm{O}=$ Origem; $\mathrm{N}=$ Nativa do Brasil; $\mathrm{E}=$ Exótica.

Dos indivíduos avaliados, $81,4 \%$ sofreram algum tipo de poda, sendo mais frequente a poda pesada $(61,6 \%)$, seguida da poda leve $(29 \%)$ e drástica $(9,4 \%)$. As espécies que mais sofreram podas pesadas foram: Bauhinia forficata, Spathodea campanulata, Michelia champaca e Licania tomentosa respectivamente (Figura 1).

As podas realizadas em Spathodea campanulata não são justificadas, devido a inexistência de conflitos com a estrutura urbana, tais como, bifurcação abaixo de 1,8 m, placas de sinalizações, construções ou rede elétrica. Em alguns indivíduos de Michelia champaca há marcas de podas em galhos com altura inferior a 1,8 m, justificando-se a poda de levantamento, embora o correto seja a poda de formação nos indivíduos ainda jovens. As espécies Bauhinia forficata e Licania tomentosa, apresentaram conflitos com a rede elétrica, sendo a principal motivação para podas. A ausência de podas foi identificada nas palmeiras, na qual é incomum a pratica dessa atividade e em poucos exemplares de Murraya paniculata e Lagerstroemia 
indica, espécies de menor porte.

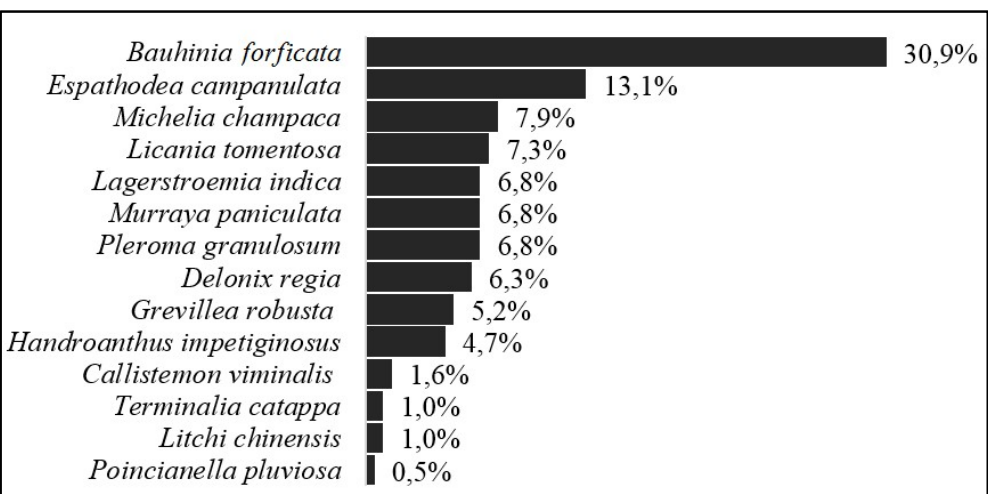

Figura 1: Porcentagem de espécies que sofreram poda pesada na arborização viária do Campus da UFV.

Dentro das categorias de podas citadas, identificou-se a poda de levantamento em $8,1 \%$ dos indivíduos das seguintes espécies: Pleroma granulosum, Bauhinia forficata e Handroanthus serratifolius. Das espécies que mais sofreram este tipo de poda está a Pleroma granulosum com $77,8 \%$ dos seus indivíduos nessa categoria. Embora tenha sido feito o levantamento em grande parte dos indivíduos dessa espécie, $52,5 \%$ ainda apresentaram altura da primeira bifurcação inferior a $1,8 \mathrm{~m}$, não se enquadrando nas recomendações técnicas desejáveis. Vale ressaltar que é possível que os indivíduos tenham passado por poda de levantamento no viveiro, quando ainda mudas, não sendo possível identifica-la na fase adulta. Dos 9,4\% de indivíduos que sofreram podas drásticas, de destopo, Michelia champaca foi a espécie que teve mais indivíduos representados (55,9\%), (Figura 2).

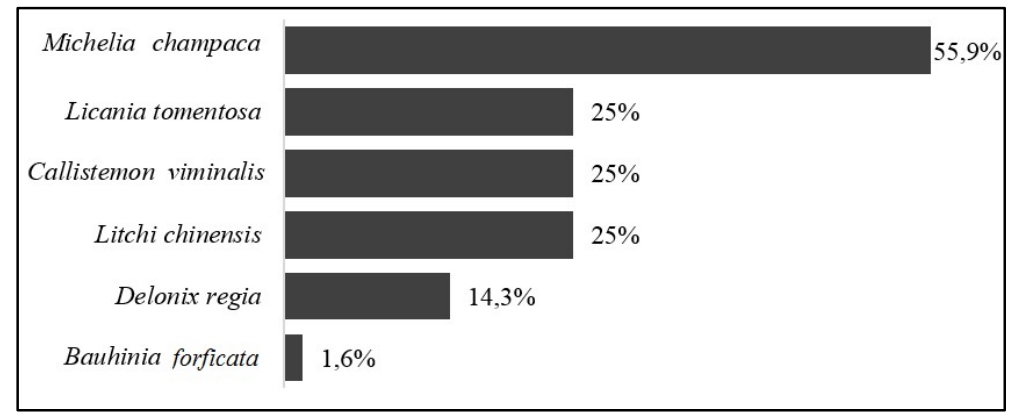

Figura 2: Espécies da arborização viária do Campus da UFV que sofreram poda drástica

Quanto à necessidade de podas realizadas, constatou-se que 65,4\% dos indivíduos não precisavam deste tipo de intervenção, sendo observadas algumas características que justificam a ausência da necessidade de podas, como: altura de bifurcação superior a 1,8 m e ausência de conflitos com a rede aérea. Dentre os indivíduos que apresentaram motivos para tal prática, 53\% necessitam de poda de desobstrução da rede aérea, $28,8 \%$ de poda de levantamento e $18,8 \%$ dos 2 tipos de poda (levantamento e desobstrução).

Outra análise realizada sobre o manejo da arborização foi referente à necessidade de remoção. Neste caso, a remoção foi indicada para $7,2 \%$ dos indivíduos, onde $2,1 \%$ já se encontravam mortos. Archontophoenix cunninghamiana (5 indivíduos), Grevilha robusta (2 indivíduos) e Spathodea campanulata (1 indivíduo), foram indicadas para remoção por apresentarem oco na base ou ao longo do tronco, gerando ponto de fragilidade, comprometendo a estrutura e com risco de quebra. Cinco indivíduos de Delonix regia 
apresentam sérios problemas como regiões ocas ou podres ao longo do tronco e/ou galhos mais grossos, além de muitos galhos mortos. Outros fatores que levaram a indicação de remoção foram: lesões significativas ao longo do fuste (Roystonea oleracea) que podem servir como porta de entrada de patógenos, comprometendo sua estrutura; presença de cupim; copas totalmente desvitalizadas, com área fotossintética insignificante, com poucas chances de recuperação (Handroanthus serratifolius e Murraya paniculata).

Considerando o estado fitossanitário das árvores avaliadas 72,7\% apresentaram fitossanidade satisfatória, 26\% ruim e 1,3\% boa. As espécies Pleroma granulosum, Terminalia catappa, Ligustrum lucidum e Callistemon viminalis tiveram todos os indivíduos avaliados classificados como satisfatórios, Grevillea robusta e Roystonea oleracea apresentaram respectivamente $90,9 \%$ e $80 \%$ dos indivíduos nessa classe, não apresentando agravantes que pudessem comprometer sua estrutura física ou condições fisiológicas. Dentre as espécies que apresentaram as piores condições de fitossanidade, Delonix regia foi a mais chamou atenção, pois todos os indivíduos avaliados foram classificados como ruim (Figura 3).

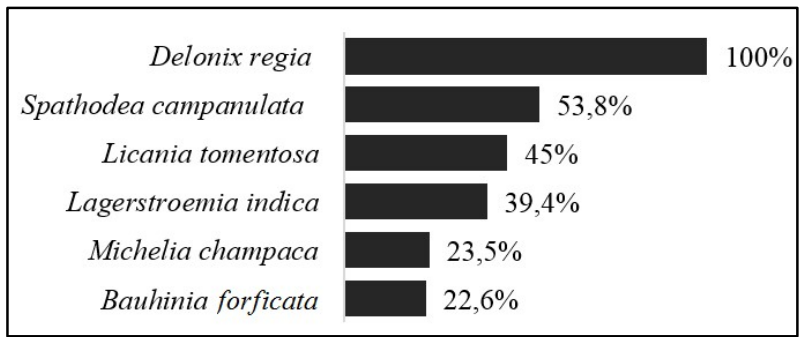

Figura 3: Espécies mais frequentes classificadas como fitossanidade ruim existentes no Campus da UFV.

Os aspectos fitossanitários negativos mais notados em Delonix regia foram: muitos galhos mortos, podas pesadas, compartimentalização incompleta levando em alguns casos a podridão dos galhos, troncos com partes ocas e poda de raízes. Spathodea campanulata foi a segunda espécie que mais se destacou, com $53,8 \%$ de indivíduos ruins, com presença de galhos mortos, podas pesadas, compartimentalizações incompletas e poda de raízes. Licania tomentosa, apresentou $45 \%$ dos indivíduos com fitossanidade ruim, com galhos mortos e manchas foliares frequentes. Dentre as espécies que apresentaram fitossanidade boa, estão Roystonea oleracea e Archontophoenix cunninghamiana, Murraya paniculata e Lagerstroemia indica.

Quanto à qualidade estética dos indivíduos $16,4 \%$ do total apresentaram ótimas condições, 37,1\% ruim, $23,5 \%$ satisfatória e $20,5 \%$ muito ruim. Entre as espécies consideradas satisfatória, $63 \%$ sofreram apenas podas leves ou não foram podadas, sendo classificadas como não podadas os indivíduos que não apresentaram marcas no tronco, contudo destaca-se que estes podem ter sofrido podas de condução ou formação na fase jovem e devido ao processo de compartimentalização completa esta ação não foi identificada. As espécies com mais indivíduos nessa categoria foram Terminalia catappa (70\%), Licania tomentosa (55\%) e Murraya paniculata (42,9\%).

As espécies com maior número de indivíduos considerados ruins, por terem suas copas descaracterizadas e aparência indesejável foram Pleroma granulosum (85,2\%) e Michelia champaca (67,6\%). Do total de indivíduos presentes nessa classe, $75,2 \%$ sofreram podas pesadas ou drásticas. Das espécies consideradas completamente deformadas, 91,3\% sofreram podas pesadas ou drásticas, sendo as espécies 
com mais indivíduos nessa categoria, Delonix regia com 100\% dos indivíduos completamente deformados, Licania tomentosa (40\%) e Michelia champaca (32\%).

Com relação ao sistema radicular, do total de árvores amostradas $82,4 \%$ possuem sistema radicular profundo, $11 \%$ superficial e 6,6\% pouco superficial. Para as espécies classificadas com o sistema radicular exposto se destacam Delonix regia com 100\% de raízes superficiais e Spathodea campanulata com 61,5\%. No caso da Spathodea campanulata, 36,5\% dos seus indivíduos possuem área livre inferior a $1 \mathrm{~m}^{2}$, apresentando danos nas calçadas.

A qualidade estrutural dos indivíduos foi avaliada com base nas condições em que o fuste e galhos se encontravam. Foi observado a presença de $37,8 \%$ de indivíduos com qualidade estrutural ruim, 35,2\% boa e $27 \%$ intermediária. Os indivíduos considerados com boas condições pertencem as espécies Roystonea oleracea (100\%) e Archontophoenix cunninghamiana (92,5\%). A presença de inclinação ou tortuosidade foi verificada em uma pequena parcela desses indivíduos em que apresentaram algum dano físico ao longo do fuste, como rachaduras ou ocos que comprometiam sua estrutura. Outra espécie com elevada frequência nessa classe foi Murraya paniculata (50\%).

$\mathrm{Na}$ classe intermediária, as espécies mais frequentes encontradas foram Licania tomentosa (75\%) Handroanthus impetiginosus (66,7\%), Michelia champaca (64,7\%) e Spathodea campanulata (61,5\%). Essas espécies apresentaram principalmente cancros ou compartimentalização incompleta, provavelmente em função das podas pesadas sofridas. Na categoria ruim ficaram as espécies Bauhinia forficata (79\%), Delonix regia $(78,6 \%)$, Pleroma granulosum $(51,9 \%)$ e Spathodea campanulata $(34,6)$. Com relação a incompatibilidade do porte das árvores com a rede aérea, foram identificados $24,7 \%$ de conflitos. As espécies que apresentaram tal incompatibilidade estão descritas na Figura 4.

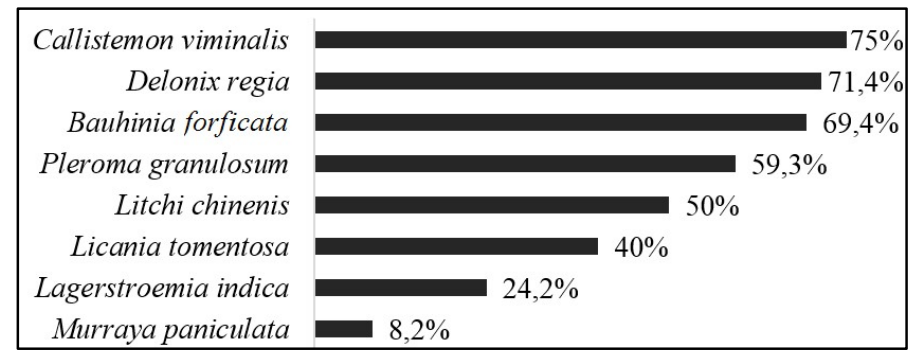

Figura 4: Porcentagem de indivíduos da arborização viária em conflito com a rede área no Campus da UFV.

Callistemon viminalis, apresentou altura média de $8 \mathrm{~m}$ e embora seja classificada como uma espécie de pequeno porte, $75 \%$ dos seus indivíduos apresentaram conflito com a rede aérea. Outras espécies de porte semelhante como Murraya paniculata e Lagerstroemia indica alcançaram alturas máximas de $4 \mathrm{~m}$ a 7 $m$, sendo suficiente para entrar em conflito com a rede aérea, mesmo estando na lista de espécies indicadas para esse tipo de situação. As demais espécies de médio porte, são inadequadas ao plantio sob a rede aérea por apresentarem maior potencial de conflitos.

Em relação a rede subterrânea constatou-se que 69,8\% dos indivíduos não apresentavam conflitos com a rede subterrânea, e os demais indivíduos ou estavam plantados no mesmo alinhamento da rede ou a uma distância que variou de 0,3 m a 2 m. Sobre a área de canteiro, 96,9\% dos canteiros apresentaram área 
superior a $1 \mathrm{~m}^{2}$, sendo que do total de indivíduos com sistema radicular profundo, $99 \%$ deles estavam plantados em canteiros com mais de $1 \mathrm{~m}^{2}$ de área livre.

Com relação à altura de bifurcação, 62,2\% dos indivíduos apresentaram bifurcação acima de 1,8 m, 21,3\% com bifurcação abaixo de 1,8 m e 16,5\% não apresentam bifurcação, sendo este último, palmeiras. Ressalta-se que em $8,1 \%$ do total de indivíduos amostrados, foi identificada a poda de levantamento, o que pode ter contribuído para elevada porcentagem de indivíduos com bifurcação superior a 1,8 m. As espécies Murraya paniculata, Pleroma granulosum, Bauhinia forficata e Lagerstroemia indica, foram as que apresentaram maiores frequência de altura de bifurcação inadequadas (Figura 5). Todos os indivíduos classificados com bifurcação ausente, pertencem a família Arecaceae.

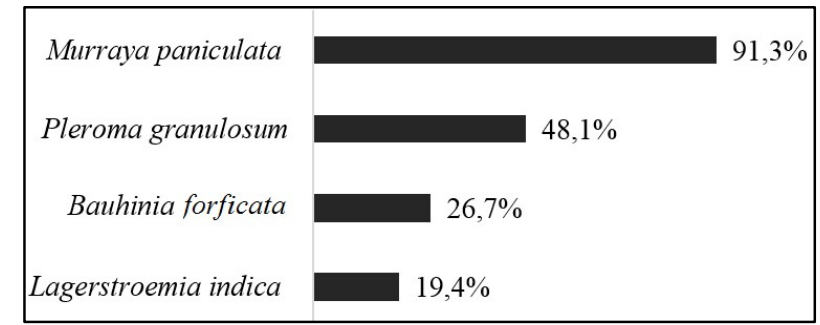

Figura 5: Espécies com bifurcação abaixo de 1,80m.

As calçadas das áreas amostradas foram divididas em classes de larguras, variando de 1,2 m a 5,8 m (Figura 6). A largura média apresentada foi de 2,6 m.

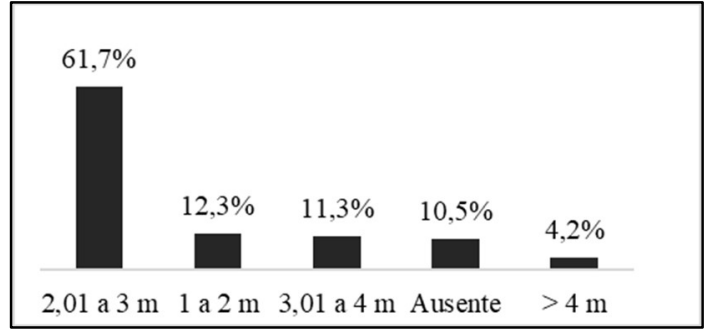

Figura 6: Indivíduos por classe de largura de calçada arborizadas no Campus da UFV.

Das espécies plantadas nas calçadas até $4 \mathrm{~m}$ de largura, Callistemon viminalis, Lagerstroemia indica e Murraya paniculata, consideradas de pequeno porte, Michelia champaca, Pleroma granulosum, Bauhinia forficata, Handroanthus serratifolius, Handroanthus impetiginosus, Litchi chinensis, de médio porte atendem estas especificações. Licania tomentosa, Ligustrum lucidum, e Grevillea robusta, espécies de médio porte, Poincianella pluviosa var. peltophoroides, Delonix regia e Spathodea campanulata consideradas de grande porte apresentaram danos ao calçamento. As palmeiras embora sejam de grande porte não apresentaram problemas.

\section{DISCUSSÃO}

O número de espécies encontradas indica uma boa variedade, uma vez que Milano et al. (2000) recomendam um número entre 10 e 20 espécies para compor a arborização de uma cidade.

A maioria das espécies encontradas são exóticas $(66,7 \%)$ assim como já encontrado em várias cidades do Brasil, como Maringá/PR (50\%), Chapadão do Sul-MS (51,6\%) Curitiba-PR (58,93\%), Ponta Grossa- 
PR (64,4\%) e Ampére-PR (85,95\%) (LOCASTRO et al., 2015; PELEGRIM et al., 2012; BOBROWSKI, 2011; MIRANDA et al., 2009; SOARES et al., 2019). Essa situação comum entre os municípios brasileiros, não obriga a exclusão dessas espécies do planejamento da arborização urbana, entretanto há de se atentar não apenas para a parte estética, mas também para a promoção dos serviços ambientais e interação com a fauna nativa, que pode ser colocado em risco devido ao uso constante de espécies exóticas (PAIVA, 2009).

O elevado percentual de podas pesadas resultante da retirada de galhos maiores, indica uma ineficiência no manejo da arborização, pois as podas deveriam ter sido realizadas nos indivíduos jovens para diminuir o risco de danos que são provocados quando realizada na fase adulta (FILIK et al., 2007). O número excessivo de poda de destopo em Michelia champaca foi preocupante, pois não foram identificados motivos aparentes execução de tal poda.

Embora as espécies Licania tomentosa, Litchi chinensis, Callistemon viminalis, e Delonix regia tenham apresentado necessidade de poda devido aos conflitos com a rede aérea, não é recomendado o destopo, devendo ser utilizado como alternativa a poda direcional. Essa modalidade de poda retira os galhos que crescem em direção a fiação ou outras instalações (CEMIG, 2011). A porcentagem de podas drásticas encontradas no Campus foi superior ao encontrado em algumas cidades como Senador Guiomard-AC, com 2,8\% (MARANHO et al., 2012) e em Várzea Grande/MT, com 4\% das árvores (MOURA et al., 2009).

Segundo a Prefeitura de São Paulo (2012), a arborização urbana deveria restringir-se a podas de formação, de limpeza (eliminação de galhos mortos ou danificados) e de emergência, quando colocam em risco a segurança dos transeuntes e poda de adequação, quando apresentam potencial de interferência em elementos urbanos, evitando que as árvores sejam mutiladas. Além disso, quando necessárias, as podas de manutenção devem ser realizadas por profissionais habilitados, pois a utilização de técnicas inadequadas de podas pode afetar a arquitetura da árvore, expô-la a patógenos (MARTINS et al., 2010) e causar aspectos estéticos desagradáveis. Outro problema ocasionado por esse tipo de poda são as brotações epicórmicas, que consiste na emissão de galhos mais frágeis na região do corte como medida de compensação, podendo quebrar mais facilmente e provocar acidentes.

Quanto a necessidade de remoção, além dos indivíduos mortos, é recomendada a remoção de árvores que sofreram ataques de cupins, que apresentam rachaduras no tronco ou que estejam inseridas em locais inadequados, causando transtornos ou riscos a população (ZAMPRONI, 2017). Ressalta-se, no entanto, que uma análise especifica e mais criteriosa deve ser realizada nesses indivíduos para validar a real necessidade de remoção.

Uma proporção significativa de indivíduos classificados como fitossanidade ruim foi encontrada, principalmente devido a presença de galhos mortos e manchas foliares. Esses aspectos comprometem as estruturas físicas e fisiológicas das árvores que passam a requerer grande esforço caso opte por recuperálos, sendo indicado, em alguns casos, a substituição por indivíduos jovens e sadios, conduzindo-os adequadamente, a fim de evitar conflitos com os elementos urbanos, principais responsáveis pela necessidade de ações corretivas que comprometem a qualidade da arborização.

Foi possível observar em grande parte dos casos, relação entre a qualidade estética e as podas 
realizadas. Das espécies que se enquadram em boa qualidade, estão predominantemente as palmeiras que não sofreram podas, não havendo, portanto, descaracterização de suas copas.

A arborização viária do Campus não apresenta graves conflitos entre calçamento e raízes, já que a maior parte dos indivíduos possuem sistema radicular profundo. Delonix regia, é uma espécie de grande porte e apresenta raízes superficiais no ambiente urbano, não sendo indicada neste caso, porém no local amostrado não houve danos ao calçamento devido a extensa área de canteiro e distância em que as calçadas se encontram das raízes, uma situação peculiar que não se repete em todas as amostras do Campus onde a espécie está presente, causando sérios danos ao calçamento em outros trechos. A inadequação da área livre combinada com espécies de sistema radicular pouco profundo além de provocar mau desenvolvimento das plantas pode comprometer a manutenção das calçadas (RABER et al., 2010).

Alguns problemas estruturais foram observados, como inclinação e tortuosidade. Tais problemas merecem atenção, uma vez que espécies com tortuosidade e inclinação acentuada, quando combinados a presença de podas pesadas tornam-se susceptíveis a queda (MODENA et al., 2011). Essas tortuosidades apresentadas são decorrentes principalmente do manejo inadequado como falta de tutoramento quando ainda mudas, podendo afetar a acessibilidade de pedestres nas calçadas e o fluxo de veículos (BIONDI, 2011).

Na maioria dos casos, os conflitos com a rede aérea foi a principal justificativa para realização de podas na arborização de ruas, sendo este um dos problemas mais comuns de compatibilização entre a arborização e elementos urbanos $(\mathrm{SCHUCH}, 2006)$. As espécies de pequeno porte, são comumente recomendadas para serem plantadas sob a rede aérea, com intuito de evitar podas que comprometam a estética e sanidade dos indivíduos. Quando alguma espécie apresenta potencial de conflito a realização de podas frequentes torna-se necessária.

Para evitar o conflito entre árvores e redes subterrâneas, Pivetta et al. (2002) indicam que o plantio seja feito de $1 \mathrm{~m}$ a $2 \mathrm{~m}$ de distância da rede subterrânea para evitar que as raízes causem problemas, enquanto o Manual de Arborização Urbana da Cemig, indica que o plantio seja realizado a 0,60 m de tubulações. Além disso, a adequação do espaço para o desenvolvimento das raízes é a maneira mais eficiente de evitar problemas com o calçamento (PERIOTTO et al., 2016), sendo recomendado uma área de canteiro de no mínimo $1 \mathrm{~m}^{2}$.

Já a altura de bifurcação está relacionada ao padrão de qualidade das mudas utilizadas na arborização (MILANO, 1984), sendo 1,8 $\mathrm{m}$ a altura mínima indicada para não ocorrência de problemas ao transito de pedestres no local (LIMA NETO, 2014), além de evitar obstrução da visão dos usuários em relação a placas de sinalização existentes. Segundo Maria (2017), a presença de bifurcação abaixo de 1,8 m indica condução inadequada das mudas desde sua formação no viveiro até o plantio, não apresentando padrão suficiente para arborização urbana.

A presença de bifurcação inferior a 1,8 m é comum em espécies de pequeno a médio porte, como as que foram identificadas no Campus, tal fato evidencia a importância de conhecer as características das espécies utilizadas, a fim de reduzir futuros gastos com manutenção e até mesmo danos físicos causados em decorrência de manejo inadequado. 
A adequação entre o porte da árvore e a largura da rua e calçada é importante para a implantação da arborização viária. Para a média encontrada no campus, Maria (2017) recomenda o plantio de espécies arbóreas de pequeno e médio porte de modo que não interfiram na acessibilidade e mobiliário urbano, já o plantio de espécies de grande porte é recomendado em calçadas com mais de $4 \mathrm{~m}$ de largura.

\section{Adequação das Espécies Plantadas}

Callistemon viminalis, com altura média de $8 \mathrm{~m}$, não foi uma espécie adequada ao plantio sob a fiação aérea devido aos conflitos encontrados. Estes conflitos levaram a necessidade de podas, resultando em perda estética, com descaracterização da copa e aparência indesejável, evidenciando também o manejo inadequado. Em locais onde não há fiação aérea a espécie não apresentou problemas. Também não é indicado seu plantio em calçadas estreitas pois sua copa pendente pode dificultar o transito de pessoas no local.

Spathodea campanulata por ser de grande porte, não é recomendada para plantio no acompanhamento viário, devido ao potencial elevado de causar danos ao calçamento em função do surgimento de raízes superficiais, fato este verificado em alguns locais do Campus, além da possibilidade de causar conflitos com a rede elétrica. No entanto em locais onde a área de canteiro é maior e ausência de rede, não houve problemas. Também apresentou problemas com manejo inadequado, evidenciado por podas pesadas, sem aparente necessidade. Esta espécie é considerada invasora, desde ambientes abertos, degradados por agricultura, sobre pastoreio até sub-bosques de florestas secundárias (INSTITUTO HORUS, 2018), não recomendado o plantio próximos a estes locais.

Delonix regia não é recomendada para plantio em calçadas, pois trata-se de uma espécie de grande porte e com raízes superficiais. No Campus, apresentou conflitos frequentes com a rede elétrica que motivaram podas drásticas. Em locais onde a área de canteiro era elevada, as raízes superficiais não apresentaram problemas, entretanto em área de canteiro pequeno, suas raízes provocaram muitos danos as calçadas, e dificultam a acessibilidade.

Grevillea robusta com altura média de $8 \mathrm{~m}$, não apresentou problemas significativos no local, porém as raízes classificadas como pouco superficiais causaram leves danos ao calçamento, por esse motivo, recomenda-se aumentar a área de canteiro. Ressalta-se também, que tal espécie não deve ser plantada embaixo da rede elétrica. Também é uma espécie considerada invasora em ambientes como áreas degradadas de florestas, pastagens, principalmente em regiões secas (INSTITUTO HORUS, 2018).

Litchi chinensis com altura média de 8,5 m, apresentou conflito com a rede elétrica, além de raízes superficiais, não sendo recomendado seu plantio sob fiação e em locais com canteiros pequenos. Para eliminar os conflitos com a rede elétrica foram realizadas poda de destopo, sendo mais adequado nesses casos a poda direcional, menos prejudicial a planta.

Bauhinia forficata, espécie bastante utilizada no Campus, apresentou muitos conflitos com a rede elétrica, não sendo recomendado o plantio sob a mesma, além de plantio realizado muito próximo a rede subterrânea. Em locais onde a rede elétrica é ausente não há problemas quanto a sua utilização. Com relação 
ao manejo, grande parte dos indivíduos apresentaram tortuosidade acentuada ao longo do fuste, indicando a falta de tutoramento na fase de mudas.

Pleroma granulosum, árvore de pequeno porte, chama atenção pela sua floração, aspecto agradável para arborização urbana, possui raízes profundas, não apresentado problemas ao calçamento, sendo apenas, contraindicado o seu plantio sob redes aéreas, para evitar conflitos como os observados no Campus.

Lagerstroemia indica, espécie de porte pequeno, apresentou conflitos com a rede aérea em alguns locais, e em outros se mostrou adequada em relação a essa variável. Também foi observado o baixo vigor das copas, no geral desfolhadas, com aspecto desagradável, contrário ao observado nessa espécie, que possui floração exuberante. Este fato pode ser explicado pela falta de adubação ou baixa adaptabilidade da espécie ao local, dada sua origem exótica.

Murraya paniculata, mesmo sendo uma espécie de porte pequeno, em alguns locais alcançou altura suficiente para entrar em conflito com a rede aérea, o que prejudica sua indicação para uso sob fiação. Destaca-se também que possui tronco muito ramificado e com altura de bifurcação abaixo do recomendado, não sendo indicado o plantio em calçadas estreitas para evitar transtornos aos pedestres.

Terminalia catappa, não apresentou graves conflitos com a estrutura urbana do Campus, causando apenas um leve levantamento em alguns trechos da calçada, mas que não foram suficientes para dificultar a acessibilidade, porém em locais onde os canteiros são menores a possibilidade de danos as calçadas aumentam. Esta espécie também é considerada invasora, principalmente em ambientes costeiros e com solos arenosos (INSTITUTO HORUS, 2018).

Handroanthus serratifolius, é uma espécie de grande porte, sendo adequada em locais com rede aérea ausente. Possui raízes profundas, diminuindo riscos de danificar as calçadas, e tem grande valor decorativo devido a sua floração amarela exuberante. Não apresentou conflitos com a estrutura urbana, se mostrando adequada ao local, porém muitos indivíduos jovens apresentaram baixo vigor, como diâmetros inferiores aos demais de idade semelhante, copas desvitalizadas e pouca folhagem. Uma explicação pode ser tratos silviculturais inadequados, como por exemplo a adubação, que usualmente é feita apenas no momento do plantio.

Handroanthus impetiginosus com características semelhantes a Handroanthus serratifolius, não apresentou sérios problemas a estrutura urbana, exceto pelo fato de estar plantada a um metro da rede subterrânea, o que pode não ser um problema devido a profundidade das raízes.

Licania tomentosa apresentou sérios conflitos com a rede elétrica, que motivaram podas de adequação, em alguns casos deformando por completo a copa dos indivíduos, não sendo indicado o plantio nesses casos. Outro problema menos frequente foi o surgimento de raízes superficiais causado danos leves as calçadas em alguns trechos e quedas de frutos médios e escorregadios na época de chuva.

Michelia champaca, embora tenha sofrido sucessivas podas, sem motivos aparentes, culminando na descaracterização da espécie, não apresentou conflitos com a estrutura urbana, não havendo empecilhos para sua utilização no local onde se encontra.

Anadenanthera colubrina apresenta acúleos ao longo do tronco, não sendo indicada para arborização 
de ruas, além de apresentar baixo número de indivíduos nas vias do Campus, não sendo suficiente para emitir parecer mais específico, fato este que também foi verificado com a espécie Poincianella pluviosa.

Ligustrum lucidum, não apresentou nenhum conflito com a estrutura urbana. Ressalta-se, no entanto, que não deve ser plantado sob rede elétrica, a menos que um plano de podas seja efetivamente criado. Esta espécie é considerada invasora, principalmente em áreas degradadas ao longo de rodovias, em terrenos baldios, bordas de plantações florestais e ecossistemas florestais, especialmente quando alterados (INSTITUTO HORUS, 2018).

Roystonea oleracea é uma espécie adequadas para arborização urbana, desde que não seja plantada sob rede elétrica. Archontophoenix cunninghamiana, embora não tenha apresentado limitações quanto a estrutura urbana, é considerada uma espécie invasora em sub-bosque de florestas secundárias e ambientes ripários (INSTITUTO HORUS, 2018), não sendo indicado o seu plantio próximos a fragmentos florestais, como foi observado no Campus.

Todas as espécies foram avaliadas em relação aos conflitos presentes na estrutura urbana do Campus e para que sejam utilizadas na arborização viária de outros locais é de suma importância conhecer suas características, a fim de verificar a compatibilidade das espécies com a estrutura urbana.

\section{CONCLUSÕES}

A arborização viária do Campus da Universidade Federal de Viçosa é composta por 19 espécies pertencentes a 13 famílias. Apenas cinco delas não apresentaram conflito com os elementos urbanos ou características que limitassem seu uso em calçadas: Handroanthus serratifolius, Handroanthus impetiginosus, Michelia champaca, Roystonea oleracea e Ligustrum lucidum.

Os danos causados ao calçamento não foram significativos, havendo baixa incompatibilidade com as espécies, assim como os conflitos com a rede subterrânea. Os conflitos com a rede aérea, ocasionados principalmente pelo porte inadequado das espécies plantadas sob a fiação, indicam a necessidade de melhores condições de manejo, bem como correto planejamento de podas, necessário desde a fase jovem das árvores.

Os principais conflitos encontrados foram com as espécies Spathodea campanulata e Delonix regia e, portanto, tais espécies não são indicadas para o plantio no acompanhamento viário. Alguns indivíduos de Litchi chinensis, Terminalia catappa, Licania tomentosa e Grevillea robusta apresentaram raiz pouco superficial, não sendo recomendado o plantio nestes locais, devido ao indicio de levantamento das calçadas, que podem gerar transtornos maiores.

De modo geral houve falta de planejamento prévio na escolha das espécies em relação ao local de plantio, culminado em muitos conflitos que não foram bem manejados, principalmente em relação a falta de qualidade técnicas das operações de poda. É necessário um melhor planejamento e manejo da arborização do Campus visando aumentar a adequação e qualidade das espécies. 


\section{REFERÊNCIAS}

ALMEIDA, L. T.; MONTEIRO, L. I. B.; SILVA, F. B.; de Paula CORRÊDO, L.; CESTONETTO, L. B.. Locação de corredores ecológicos e área de preservação permanente na Universidade Federal de Viçosa. Nativa, Sinop, v.4, n.6, p.412-418, 2016. DOI: http://dx.doi.org/10.14583/2318$\underline{7670 . v 04 n 06 a 12}$

BASSO, J. M.; CORRÊA, R. S.. Arborização urbana e qualificação da paisagem. Paisagem e Ambiente, São Paulo, n.34, p.129-148, 2014. DOI:

https://doi.org/10.11606/issn.2359-5361.v0i34p129-148

BIONDI D.. Floresta urbana: conceitos e terminologias. In: BIONDI, D.. Floresta urbana. Curitiba, 2015.

BIONDI, D.. Arborização urbana: aplicada à educação ambiental nas escolas. Curitiba, 2008.

BIONDI, D.. Introdução de espécies na arborização de ruas. In: BIONDI, D.. Pesquisa em arborização de rua. Curitiba: 2011. p.9-28.

BOBROWSKI, R.. Estrutura e dinâmica da arborização de ruas de Curitiba, Paraná, no período 1984-2010. Dissertação (Mestrado em Engenharia Florestal) - Universidade Federal do Paraná, Curitiba, 2011.

CASTRO, P. S.; VALENTE, O. F.; COELHO, D. T.; RAMALHO, R. S.. Interceptação da chuva por mata natural secundária na região de Viçosa, MG. Revista Árvore, Viçosa, v.7, n.1, p.7689, 1973.

CEMIG. Manual de arborização. Belo Horizonte: CEMIG, 2011.

ESCOBEDO, F.; ANDREAU, M.. A community guide to Urban Forest Inventóries. Florida: University of Florida, 2008.

FILIK, A.; SILVA, L. F.; LIMA, A. M. L. P.. Avaliação da arborização de ruas do bairro são dimas na cidade de Piracicaba/SP através de parâmetros qualitativos. Revista da sociedade brasileira de arborização urbana, Piracicaba, v.2, n.1, p.34-43, 2007. DOI:

http://dx.doi.org/10.5380/revsbau.v2i1.66234

INSTITUTO HORUS. Base de dados de espécies exóticas invasoras do Brasil. Florianópolis: Instituto Hórus, 2019.

LIMA NETO, E. M.. Índices e métricas para a gestão das árvores de rua de Boa Vista-RR a partir de cadastro espacial. Tese (Doutorado em Ciências Agrárias) Universidade Federal Paraná, Curitiba, 2014.

LOCASTRO, J. K.; ANGELIS, B. L. D.. Diagnóstico qualiquantitativo da arborização de acompanhamento viário em avenidas de Maringá-PR. Revista eletrônica em gestão, educação e tecnologia ambiental, Santa Maria, v.19, n.3, p.248-255, 2015. DOI:

http://dx.doi.org/105902/2236117018366

MARANHO, Á. S.; PAULA, S. R. P.; LIMA, E.; PAIVA, A. V.; ALVES, A. P.; NASCIMENTO, D. O.. Levantamento censitário da arborização urbana viária de Senador Guiomard, Acre. Revista da Sociedade Brasileira de Arborização Urbana,
Piracicaba, v.7, n.3, p.44-56, 2012. DOI:

http://dx.doi.org/10.5380/revsbau.v7i3.66532

MARIA, T. R. B. D. C.. Inventário quali-quantitativo de arborização viária do município de Itanhaém-SP. Dissertação (Mestrado em Engenharia Florestal). Universidade Federal do Paraná, Curitiba, 2017.

MARTINS, L. F. V.; ANDRADE, H. H. B.; ANGELIS, B. L. D.. Relação entre podas e aspectos fitossanitários em árvores urbanas na cidade de Luiziana, Paraná. Revista da Sociedade Brasileira de Arborização Urbana, Piracicaba, v.5, n.4, p.141155, 2010. DOI:

http://dx.doi.org/10.5380/revsbau.v5i4.66324

MELO, R. R.; LIRA FILHO, J. A.; RODOLFO JÚNIOR, F..

Diagnóstico qualitativo e quantitativo da arborização urbana no bairro Bivar Olinto, Patos, Paraíba. Revista da Sociedade Brasileira de Arborização Urbana, Piracicaba, v.2, n.1, p.6478, 2007. DOI:

http://dx.doi.org/10.5380/revsbau.v2i1.66241

MENEGHETTI, G. I. P.. Estudo de dois métodos de amostragem para inventário da arborização de ruas dos bairros da orla marítima do município de Santos, SP. Dissertação (Mestrado em Recursos Florestais) Universidade de São Paulo, São Paulo, 2003.

MILANO, M S.. Avaliação e Análise da Arborização de Ruas de Curitiba/PR. Dissertação (Mestrado em Ciências Florestais) - Universidade Federal Paraná, Curitiba, 1984.

MILANO, M.; DALCIN, E.. Arborização de vias públicas. Rio de Janeiro: LIGHT, 2000.

MIRANDA, T. O.; CARVALHO, S. M.. Levantamento quantitativo e qualitativo de indivíduos arbóreos presentes nas vias do bairro da Ronda em Ponta Grossa/PR. Revista da Sociedade Brasileira de Arborização Urbana, Piracicaba, v.4, n.3, p.143-157, 2009. DOI:

http://dx.doi.org/10.5380/revsbau.v4i3.66436

MODENA, C. M.; ROSSATO, M.. Caracterização morfológica de Chinus molle L., pertencente ao bando ativo de germoplasma da Universidade de Caxias do Sul. In: ENCONTRO DE JOVENS PESQUISADORES. Anais. Caxias do Sul, 2011.

MOURA, T. A.; SANTOS, V. L. L. V.. Levantamento quantitativo de espécies arbóreas e arbustivas na arborização urbana dos bairros Centro e Centro Norte de Várzea Grande - Mato Grosso. Revista da Sociedade Brasileira de Arborização Urbana, Piracicaba, v.1, n.1, p.97117, 2009. DOI:

http://dx.doi.org/10.5380/revsbau.v4i2.66406

OLIVEIRA FILHO, A. T.; VILELA, E. D. A.; GAVILANESS, M. L.; CARVALHO, D. D.. Comparison of the woody flora and soils of six areas of montane semideciduous forest in southern Minas Gerais, Brazil. Edinburgh Journal of Botany, Edimburgo, v.51, n.3, p.355-389, 1994. DOI: https://doi.org/10.1017/S0960428600001839

PAIVA, A. V.. Aspectos da arborização urbana do centro de Cosmópolis-SP. Revista da Sociedade Brasileira de 
Arborização Urbana, Piracicaba, v.4, n.4, p.17-31, 2009. DOI: http://dx.doi.org/10.5380/revsbau.v4i4.66446

PELEGRIM, E. A. L.; LIMA, A. P. L.; LIMA, S. F.. Avaliação qualitativa e quantitativa da arborização no bairro de Flamboyant em Chapadão do Sul, MS. Revista da Sociedade Brasileira de Arborização Urbana, Piracicaba, v.7, n.1, p.126-142, 2012. DOI:

http://dx.doi.org/10.5380/revsbau.v7i1.66549

PERIOTTO, F.; PITUCO, M. M.; HELMANN, A. C.; SANTOS, T.; BORTOLOTTI, S. L.. Análise da arborização urbana no município de Medianeira, Paraná. Revista da Sociedade Brasileira de Arborização Urbana, Piracicaba, v.11, n.2, p.5974, 2016. DOI:

http://dx.doi.org/10.5380/revsbau.v11i2.63428

PIVETTA, K. F. L; SILVA FILHO, D. F.a. Arborização urbana. Jaboticabal: UNESP, 2002.

RABER, A. P; REBELATO, G. S.. Arborização viária do município de colorado, RS-Brasil: análise qualiquantitativa. Revista da Sociedade Brasileira de Arborização Urbana, Piracicaba, v.5, n.1, p.183-99, 2010. DOI: http://dx.doi.org/10.5380/revsbau.v5i1.66260

REZENDE, T. M.; SANTOS, D. G.. Avaliação quali-quantitativa da arborização das praças do bairro Jaraguá, UberlândiaMG. Revista da Sociedade Brasileira de Arborização Urbana, Piracicaba, v.5, n.2, p.139-157, 2010. DOI: http://dx.doi.org/10.5380/revsbau.v5i2.66275
RIBEIRO, F. A. B. S.. Arborização urbana em Uberlândia: percepção da população. Revista da Católica, Uberlândia, v.1, n.1, p.224-237, 2009.

SÃO PAULO. Manual técnico de poda de árvores. Secretária do Verde e Meio Ambiente. São Paulo: Secretária de Coordenação de Subprefeituras, 2012.

SCHUCH, M. I. S.. Arborização urbana: uma contribuição à qualidade de vida com uso de geotecnologias. Dissertação (Mestrado em Geomática) - Universidade Federal de Santa Maria, Santa Maria, 2006.

SILVA JÚNIOR, M. C.; LIMA, R. M. C. E.. 100 árvores urbanas Brasília: guia de campo. Rede de Sementes do Cerrado, 2010.

SILVA, A. G.; PAIVA, H. N.; GONÇALVES, W.. Avaliado a arborização urbana. Viçosa, 2007.

SOARES, J.; PELLIZZARO, L.. Inventário da arborização urbana do município de Ampére (Paraná - Brasil). Revista Brasileira de Meio Ambiente, v.5, n.11, p.111-127, 2019.

SOARES JÚNIOR, F. J.. Composição florística e estrutura da vegetação arbórea de um fragmento de Floresta Estacional Semidecidual na Fazenda Tico-Tico, Viçosa-MG. Dissertação (Mestrado em Botânica) - Universidade Federal de Viçosa, Viçosa, 2000.

ZAMPRONI, K.. Diagnóstico e percepção da arborização viária de Bonito/MS. Dissertação (Mestrado em Ciências Florestais) - Universidade Federal do Paraná, Curitiba, 2017.

A CBPC - Companhia Brasileira de Produção Científica (CNPJ: 11.221.422/0001-03) detém os direitos materiais desta publicação. Os direitos referem-se à publicação do trabalho em qualquer parte do mundo, incluindo os direitos às renovações, expansões e disseminações da contribuição, bem como outros direitos subsidiários. Todos os trabalhos publicados eletronicamente poderão posteriormente ser publicados em coletâneas impressas sob coordenação da Sustenere Publishing, da Companhia Brasileira de Produção Científica e seus parceiros autorizados. Os (as) autores (as) preservam os direitos autorais, mas não têm permissão para a publicação da contribuição em outro meio, impresso ou digital, em português ou em tradução. 